Letter to the Editor

\title{
Effect of pacemaker site on B-type natriuretic peptide levels and left ventricular function in a population with high prevalence of Chagas disease
}

\author{
Sônia Francisca de Souza a,b, Bruno R. Nascimento ${ }^{a, c, *}$, Maria do Carmo P. Nunes ${ }^{\text {a,b,c }}$, José Luiz P. da Silva ${ }^{\text {d }}$, \\ Vinícius T. de Carvalho a,c Andrea Z. Beaton ${ }^{\mathrm{e}}$, Manoel Otávio C. Rocha a,b,c ${ }^{\mathrm{a}}$, Antonio L. Ribeiro ${ }^{\mathrm{a}, \mathrm{b}, \mathrm{c}}$ \\ a Serviço de Cardiologia e Cirurgia Cardiovascular do Hospital das Clínicas da UFMG, Belo Horizonte, MG, Brazil \\ b Pós-graduação em Infectologia e Medicina Tropical, Faculdade de Medicina da UFMG, Belo Horizonte, MG, Brazil \\ c Departamento de Clínica Médica, Faculdade de Medicina da Universidade Federal de Minas Gerais, Belo Horizonte, MG, Brazil \\ d Departamento de Estatística da Universidade Federal de Minas Gerais, Belo Horizonte, MG, Brazil \\ e Children's National Health System, Washington, DC, United States
}

\section{A R T I C L E I N F O}

\section{Article history:}

Received 19 February 2015

Received in revised form 14 April 2015

Accepted 15 April 2015

Available online 17 April 2015

\section{Keywords:}

Pacemaker

Left ventricular function

Chagas disease

Artificial cardiac stimulation

\section{Dear Editor:}

The right ventricular (RV) apex has long been the most common site of endocardial pacing, due to its anterior location and technical ease of lead placement. However previous data show that RV apical pacing can cause or worsen mitral regurgitation, increase BNP levels [1] and may increase mortality [2,3]. Additionally, a dose-dependent relationship, attributed to cardiac dyssynchrony [4], has been shown between RV apical pacing and both hospitalization for heart failure and mortality $[5,6]$. Thus, alternative RV sites have been evaluated [7]. Accordingly, we aimed to assess the effects of RV pacing site (apical vs. non-apical) on functional class, left ventricular (LV) function, and serum B-type natriuretic peptide (BNP) 6 months and 1 year after lead

\footnotetext{
* Corresponding author at: Hospital das Clínicas da Universidade Federal de Minas Gerais, Rua Tenente Garro 137/1202, Santa Efigênia, Belo Horizonte, Minas Gerais, CEP 30.240-360, Brazil.

E-mail address: ramosnas@gmail.com (B.R. Nascimento).
}

placement. Uniquely, our population contains a large percentage of patients with Chagas disease, in whom the effect of RV pacing site is not well investigated.

Between January/2011 and June/2012, 70 consecutive patients referred for elective or urgent pacemaker (PM) implantation at Hospital das Clínicas, Belo Horizonte, Brazil, were approached for study participation. Patients were excluded if they did not have an echocardiogram within $24 \mathrm{~h}$ of PM implantation ( $\mathrm{n}=10$ ), or were unable to present for follow-up visits $(\mathrm{n}=4)$. Written informed consent was obtained from all patients and Institutional Review Board and Ethics Committee approval was obtained.

Baseline ( $<24$ h after PM implantation), 6-month, and 1-year followup visits included clinical evaluation, functional class determination, 12-lead EKG, serum BNP (VIDAS® NT kit, Biomerieux), and transthoracic echocardiogram (iE33, Philips Medical Systems, Andover, MA). Left ventricle systolic (LVSd) and diastolic (LVDd) diameters and ejection fraction (LVEF) were recorded.

Statistical analysis was performed using SPSS version 20.0 for Mac OSX (SPSS Inc., Chicago, Illinois). To evaluate the variation of continuous variables compared to baseline we used the paired Student's t-test or the Wilcoxon paired test. Longitudinal data analysis was performed using ANOVA, assuming interval measurement (fixed time points: baseline, 6 and 12 months) and normally distributed errors. Multivariate linear regression analysis was used to identify predictors of changes in LVSd at 12 months. p-Values $\leq 0.05$ were considered statistically significant.

Fifty-six patients met inclusion criteria, with 40 in the apical pacing group (AP) and 16 in the non-apical pacing group (NAP). Baseline characteristics, including age, gender distribution, percentage of patients with Chagas disease, drug therapy, BNP, and echocardiographic parameters were similar between groups. The NAP group had a higher proportion of New York Heart Association (NYHA) class I patients at study entry ( $44 \%$ vs. $13 \%, p=0.04$ ) (Table 1 ). Despite the proportion of symptomatic patients, only $13 \%$ in each group had left bundle branch block, and none fulfilled criteria for biventricular pacing. Among NAP patients, 12 had implants in the septum, 3 in 
Table 1

Patients baseline features according to pacing site.

\begin{tabular}{|c|c|c|c|c|}
\hline Variable & & $\begin{array}{l}\text { Non-apical pacing } \\
(\mathrm{N}=16)\end{array}$ & $\begin{array}{l}\text { Apical pacing }(\mathrm{N} \\
=40)\end{array}$ & $\mathrm{p}$ \\
\hline Age (years) & & $57.4 \pm 15.5$ & $62.7 \pm 13.3$ & 0.24 \\
\hline Male (\%) & & 25.0 & 47.5 & 0.12 \\
\hline Chagas disease & & $8(50 \%)$ & $26(65 \%)$ & 0.30 \\
\hline \multirow[t]{2}{*}{ NYHA functional class } & I & $7(44)$ & $5(13)$ & $0.010^{*}$ \\
\hline & II/III & $9(56)$ & $35(87)$ & \\
\hline \multirow[t]{3}{*}{ Symptoms } & Syncope & $1(7 \%)$ & $8(20 \%)$ & 0.06 \\
\hline & Pre-syncope & $1(7 \%)$ & $2(5 \%)$ & \\
\hline & $\mathrm{CHF}(\mathrm{N}, \%)$ & $5(33 \%)$ & $18(45 \%)$ & \\
\hline Lead displacement & & $1(6 \%)$ & $2(5 \%)$ & 0.85 \\
\hline \multirow[t]{3}{*}{ Drugs } & ACEI/ARB & $9(56 \%)$ & $25(63 \%)$ & 0.67 \\
\hline & Beta-blocker & $5(31 \%)$ & $14(35 \%)$ & 0.79 \\
\hline & Amiodarone & $2(13 \%)$ & $6(15 \%)$ & 0.81 \\
\hline Stimulation $>75 \%$ & & $13(81)$ & $31(78)$ & 0.76 \\
\hline Dual chamber (DDD) pacing & & $14(88 \%)$ & $30(75 \%)$ & 0.48 \\
\hline RBBB/LBBB $(\mathrm{N}, \%)$ & & $4(25 \%) / 2(13 \%)$ & $17(42 \%) / 5(13 \%)$ & $0.36 / 1.00$ \\
\hline QRS duration $^{\mathrm{a}}$ (ms) & & $96.3 \pm 22.2$ & $109.2 \pm 24.8$ & 0.074 \\
\hline $\mathrm{BNP}(\mathrm{pg} / \mathrm{dl})$ & & $343(78 / 1452)$ & $272(115 / 1231)$ & 0.964 \\
\hline LVDd (mm) & & $53.3 \pm 10.1$ & $56.6 \pm 7.7$ & 0.179 \\
\hline LVSd (mm) & & $37.7 \pm 11.8$ & $41.9 \pm 10.0$ & 0.186 \\
\hline $\operatorname{LVEF}(\%)$ & & $56.1 \pm 14.8$ & $49.3 \pm 16.0$ & 0.186 \\
\hline
\end{tabular}

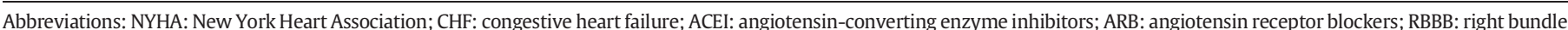

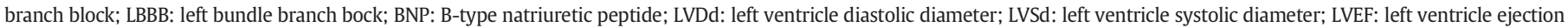
fraction.

a Before PM implantation.

* $\mathrm{p}<0,05$.

the sub-tricuspid region and 1 in the RV outflow tract. Complete atrioventricular block (48\%), advanced atrioventricular block (35\%) and atrial fibrillation (17\%) were the most frequent indications for PM.

Plasma BNP levels began to diverge at 6 months, leading to a significant increase in the AP group $(+121(-29 / 1002) \mathrm{pg} / \mathrm{dl}$, $\mathrm{p}=0.04)$ and a non-significant decrease in the NAP group $(-22$ $(-272 / 22) \mathrm{pg} / \mathrm{dl}, \mathrm{p}=0.41)$ by the 12 -month follow-up. LVSd curves also started to diverge at 6-months, with an increase in the AP, and decrease in NAP (Fig. 1), which also demonstrated a decrease in LVDd. At 12-months, LVSd and LVDd decreased significantly in NAP $(\mathrm{p}=0.04 ; \mathrm{p}<0.01)$, whereas LVSd increased in AP $(\mathrm{p}<0.01)$ (Table 2). Furthermore, the NAP group showed a significant increase in $\operatorname{LVEF}(\mathrm{p}=0.04)$, which was significantly higher in this group compared to AP after 12 months ( $58.3 \%$ vs. $46.6 \%, \mathrm{p}=0.02$ ). There was no correlation between changes in QRS width and the variation of LV parameters or BNP levels. The comparison of absolute and percent changes in BNP and LV measurements between groups is showed in Table 3. There was similar improvement in NYHA functional class for both groups (Table 2 ).

In the multivariate linear regression analysis, apical stimulation: $\beta=8.0$ (CI 95\% 0.3-15.7, $\mathrm{p}=0.042$ ) and positive Chagas serology: $\beta=-10.1$ ( $\mathrm{Cl} 95 \%-17.2$ to $-3.0, \mathrm{p}=0.006)$ were independent predictors of LVSd variation.

Our findings suggest that, in a cohort of patients undergoing PM implantation, AP pacing sites may lead to increased BNP - a marker of poor prognosis in Chagas [8] and other cardiomyopathies - and also deleterious effects on LV diameters and function compared with NAP pacing. The effect of the pacing site is reinforced by the multivariate linear regression. These data are in agreement with previous published studies that evaluated cardiac structure and function in response to various forms of artificial stimulation [1] and are especially relevant considering the particularities of a population with high prevalence of Chagas disease, another predictor of LV enlargement.

Chagas cardiomyopathy has a highly variable and sometimes relentless progression, regardless of therapy. Severe conduction disorders are among the most common complications and may occur early in the development of this cardiomyopathy [9], recognized as a leading cause of pacemaker implantation in endemic countries. In comparison with pacemaker patients without the disease, Chagas pacemaker patients are significantly younger, have a lower LVEF and more frequent ventricular arrhythmias during Holter monitoring [8]. It must be also considered that dyssynchrony resulting from AP pacing in chagasic patients may lead to or speed the increase LV diameters and BNP levels [1], resulting in functional decline and worse prognosis. This study, which included a population with high percentage of Chagas disease, urges us to further evaluate if formal recommendations are needed to optimize PM placement in this population.

While our data are compelling, there are several limitations. This was a prospective cohort design with limited sample size, and selection of PM site was the operator's choice. It is also impossible to rule out that the slightly worse baseline cardiac function in the AP group could have influenced the myocardial response to artificial pacing. Our study, like many previous, involved a heterogeneous population, limiting definite conclusions about specific patient subgroups [10, 11] (e.g. Chagas). Previous similar studies have been relatively small, with current literature showing conflicting results - some supporting that NAP results in slower progression of Chagas cardiomyopathy [10], and others showing no morphological and functional differences between NAP and AP groups at 1 year [11].

In conclusion, our findings confirm previous data, suggesting that AP pacing is detrimental to LV function, and leads to increased LV size and elevated BNP. This is contrasted by the improvement of LV diameters and function in NAP patients. The choice of NAP sites should be encouraged, and this recommendation may be particularly important to consider in patients with Chagas disease, though further studies are needed.

\section{Conflict of interest}

The authors have no conflicts of interest to disclose. 

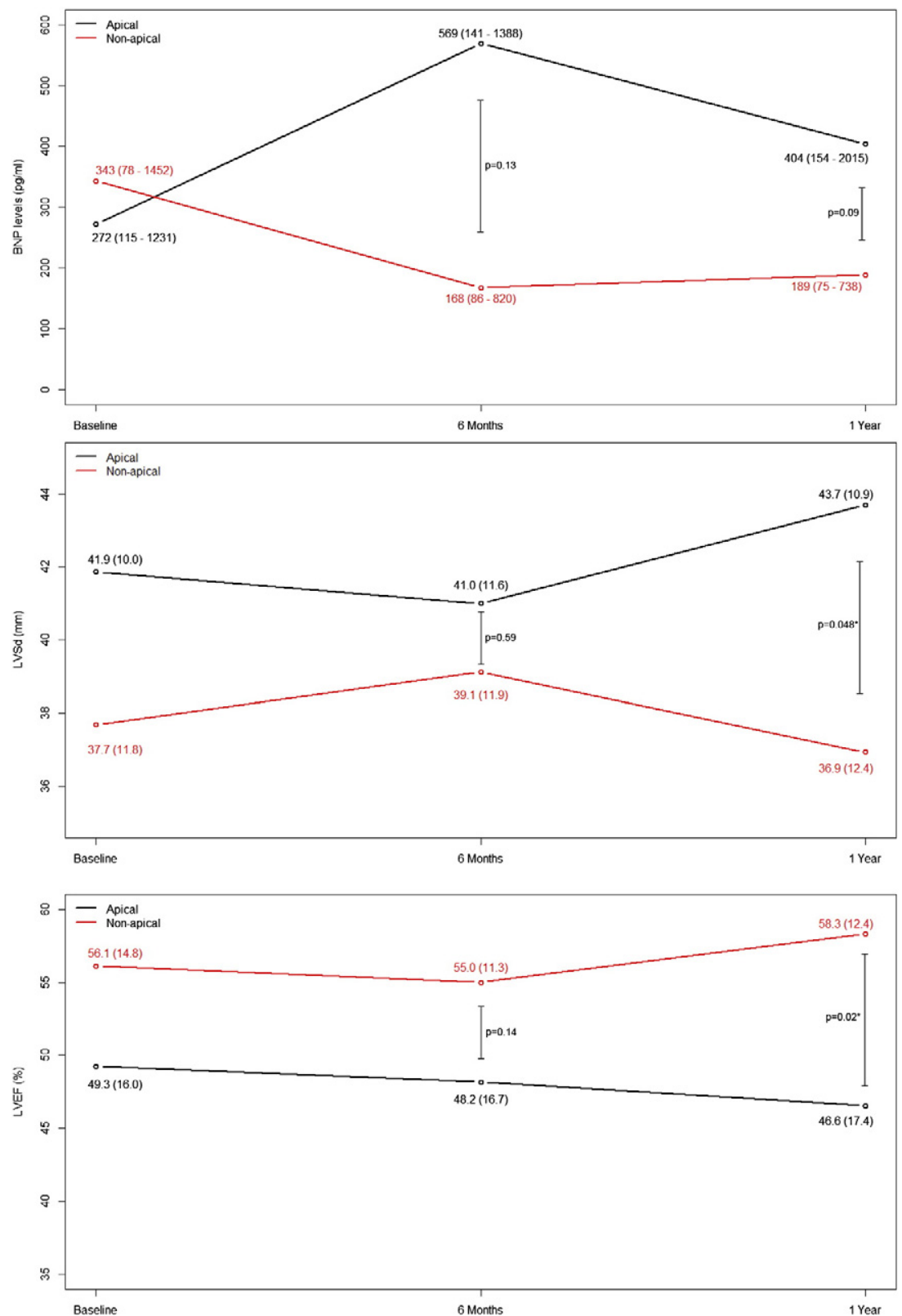

Fig. 1. Longitudinal data analysis (baseline, 6 and 12 months) of serum BNP levels, left ventricular systolic diameter (LVSd) and left ventricle ejection fraction (LVEF).

Table 2

Longitudinal data analysis of NYHA functional class, electrocardiographic and echocardiographic variables at 6-month and 12-month follow-ups.

\begin{tabular}{|c|c|c|c|}
\hline Pacing site & 6 months & 1 year & $\mathrm{p}$ (baseline to 1 year) \\
\hline \multicolumn{4}{|l|}{ Non-apical pacing } \\
\hline NYHA functional class II/III & $3(19)$ & $4(25)$ & 0.18 \\
\hline QRS duration $(\mathrm{ms})^{\mathrm{a}}$ & $111.2 \pm 18.2$ & $114.4 \pm 16.7$ & 0.24 \\
\hline $\mathrm{BNP}(\mathrm{pg} / \mathrm{dl})$ & $168(86 / 820)$ & $189(75 / 738)$ & 0.41 \\
\hline LVDd (mm) & $54.3 \pm 9.5$ & $51.4 \pm 9.5$ & $0.007^{*}$ \\
\hline LVSd (mm) & $39.1 \pm 11.9$ & $36.9 \pm 12.4$ & $0.04^{*}$ \\
\hline $\operatorname{LVEF}(\%)$ & $55.0 \pm 11.3$ & $58.3 \pm 12.4$ & $0.04^{*}$ \\
\hline \multicolumn{4}{|l|}{ Apical pacing } \\
\hline NYHA functional class II/III & $24(60)$ & $26(65)$ & 0.09 \\
\hline QRS duration $(\mathrm{ms})^{\mathrm{a}}$ & $139.5 \pm 15.8$ & $140.0 \pm 16.2$ & 0.32 \\
\hline $\mathrm{BNP}(\mathrm{pg} / \mathrm{dl})$ & $569(141 / 1388)$ & $404(154 / 2015)$ & $0.04^{*}$ \\
\hline LVDd (mm) & $55.5 \pm 8.5$ & $56.5 \pm 7.4$ & 0.13 \\
\hline LVSd (mm) & $41.0 \pm 11.6$ & $43.7 \pm 10.9$ & $0.002^{*}$ \\
\hline $\operatorname{LVEF}(\%)$ & $48.2 \pm 16.7$ & $46.6 \pm 17.4$ & 0.25 \\
\hline
\end{tabular}

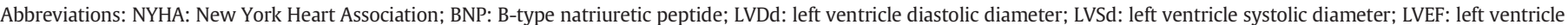
ejection fraction.

a Paced QRS.

* $\mathrm{p}<0,05$. 
Table 3

Absolute and relative changes in left ventricular measurements and BNP during follow-up according to pacing site.

\begin{tabular}{|c|c|c|c|c|c|c|}
\hline \multirow[t]{2}{*}{ Variables } & \multirow[t]{2}{*}{ Interval } & \multicolumn{2}{|l|}{ Non-apical pacing } & \multicolumn{2}{|l|}{ Apical pacing } & \multirow{2}{*}{$\frac{\mathrm{p} \text { (NAP vs. AP) }}{\text { Abs/Rel. }}$} \\
\hline & & Absolute & Relative (\%) & Absolute & Relative (\%) & \\
\hline \multirow[t]{2}{*}{$\mathrm{BNP}(\mathrm{pg} / \mathrm{dl})$} & 0-6 months & $-61(-407 / 21)$ & $-33(-57 / 18)$ & $47(-89 / 573)$ & $20(-27 / 89)$ & 0.06/0.05 \\
\hline & 0-12 months & $-22(-272 / 22)$ & $-14(-65 / 22)$ & $121(-29 / 1002)$ & $41(-31 / 148)$ & $0.014^{*} / 0.015^{*}$ \\
\hline \multirow[t]{2}{*}{ LVDd (mm) } & 0-6 months & $0(-2.0 / 2.0)$ & $0(-3.4 / 4.1)$ & $-1.0(-3.0 / 2.0)$ & $-2(-5.7 / 4.2)$ & $0.43 / 0.41$ \\
\hline & 0-12 months & $-2.5(-5.0 / 1.5)$ & $-4.2(-10 / 3.7)$ & $1.0(-3.5 / 4.0)$ & $1.6(-5.5 / 7.4)$ & $0.19 / 0.22$ \\
\hline \multirow[t]{2}{*}{ LVSd (mm) } & 0-6 months & $0(-1.5 / 4.5)$ & $0(-4.6 / 10.2)$ & $0(-2.0 / 2.0)$ & $0(-6.7 / 5.3)$ & $0.40 / 0.43$ \\
\hline & 0-12 months & $-2.0(-3.0 / 1.5)$ & $-4.2(-10.0 / 3.7)$ & $2.5(-0.5 / 6.0)$ & $1.6(-5.5 / 7.4)$ & $0.023^{*} / 0.042^{*}$ \\
\hline \multirow[t]{2}{*}{$\operatorname{LVEF}(\%)$} & 0-6 months & $-2.0(-6.5 / 4.0)$ & $-3.1(11.5 / 9.2)$ & $0.5(-5.5 / 3.5)$ & $0.9(-10.6 / 9.1)$ & $0.78 / 0.83$ \\
\hline & 0-12 months & $1.0(-2.0 / 4.5)$ & $2.5(-3.5 / 7.5)$ & $-2.5(-9.0 / 4.0)$ & $-5.4(-17.1 / 8.6)$ & $0.12 / 0.13$ \\
\hline
\end{tabular}

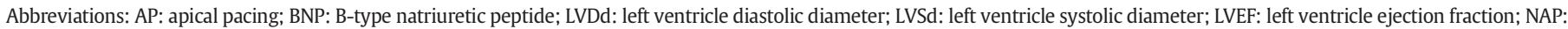
non-apical pacing.

* $\mathrm{p}<0.05$.

\section{References}

[1] C.D. Abreu, C. Nunes Mdo, M.M. Barbosa, M.O. Rocha, A.L. Ribeiro, Ventricular dyssynchrony and increased BNP levels in right ventricular apical pacing, Arq. Bras. Cardiol. 97 (2011) 156-162.

[2] G.R. Heyndrickx, J.P. Vilaine, D.R. Knight, S.F. Vatner, Effects of altered site of electrical activation on myocardial performance during inotropic stimulation, Circulation 71 (1985) 1010-1016

[3] W.C. Little, R.C. Reeves, J. Arciniegas, R.E. Katholi, E.W. Rogers, Mechanism of abnormal interventricular septal motion during delayed left ventricular activation, Circulation 65 (1982) 1486-1491.

[4] M.C. Nunes, C.D. Abreu, A.L. Ribeiro, M.M. Barbosa, L.G. Rincon, R.C. Reis, et al., Effect of pacing-induced ventricular dyssynchrony on right ventricular function, Pacing Clin. Electrophysiol. 34 (2011) 155-162.

[5] M.O. Sweeney, A.S. Hellkamp, K.A. Ellenbogen, A.J. Greenspon, R.A. Freedman, K.L. Lee, et al., Adverse effect of ventricular pacing on heart failure and atrial fibrillation among patients with normal baseline QRS duration in a clinical trial of pacemaker therapy for sinus node dysfunction, Circulation 107 (2003) 2932-2937.
[6] M.S. Link, A.S. Hellkamp, N.A. Estes III, E.J. Orav, K.A. Ellenbogen, B. Ibrahim, et al., High incidence of pacemaker syndrome in patients with sinus node dysfunction treated with ventricular-based pacing in the Mode Selection Trial (MOST), J. Am. Coll. Cardiol. 43 (2004) 2066-2071.

[7] J. Francis, B. Jayesh, M. Ashishkumar, A. Faizal, H. Mond, Right ventricular septal pacing: has it come of age? Indian Pacing Electrophysiol. J. 10 (2010) 69-72.

[8] M.F. Lima-Costa, C.C. Cesar, S.V. Peixoto, A.L. Ribeiro, Plasma B-type natriuretic peptide as a predictor of mortality in community-dwelling older adults with Chagas disease: 10-year follow-up of the Bambui Cohort Study of Aging, Am. J. Epidemiol. 172 (2010) 190-196.

[9] M.C. Nunes, W. Dones, C.A. Morillo, J.J. Encina, A.L. Ribeiro, Chagas disease: an overview of clinical and epidemiological aspects, J. Am. Coll. Cardiol. 62 (2013) 767-776.

[10] Junior O. da Silva, M.C. Borges, C.S. de Melo, G.A. Nascente, D. Correia, Alternative sites for right ventricular pacing in Chagas disease: a comparative study of the mid-septum and inflow tract, Pacing Clin. Electrophysiol. 37 (2014) 1166-1173.

[11] O. Silva Junior, P.M. Maeda, M.C. Borges, C.S. Melo, D. Correia, One-year cardiac morphological and functional evolution following permanent pacemaker implantation in right ventricular septal position in chagasic patients, Rev. Soc. Bras. Med. Trop. 45 (2012) 340-345. 